\title{
No benefit of intraoperative whole blood sequestration and autotransfusion during coronary artery bypass grafting: Results of a randomized clinical trial
}

\author{
A. N. Ramnath, $M D^{a, b}$ \\ H. R. Naber, $M D^{\mathrm{a}}$ \\ A. de Boer, MD, PhD \\ J. A. Leusink, MD, PhDa
}

From the Department of Anesthesiology and Intensive Care, ${ }^{\mathrm{a}}$ St Antonius Hospital, Nieuwegein, The Netherlands, and the Department of Pharmacotherapy and Pharmacoepidemiology, ${ }^{\text {b }}$ University of Utrecht, Utrecht, The Netherlands.

Received for publication July 30, 2001; revisions requested Oct 24, 2001; revisions received June 12, 2002; accepted for publication June 24, 2002.

Address for reprints: J. A. Leusink, MD, $\mathrm{PhD}$, Anesthesiologist, St Antonius Hospital, Department of Anesthesiology, Koekoekslaan 1, 3435 CM, Nieuwegein, Netherlands (E-mail: maatschap@anestnieuwegein.net).

J Thorac Cardiovasc Surg 2003;125:1432-7

Copyright (C) 2003 by The American Association for Thoracic Surgery

$0022-5223 / 2003 \$ 30.00+0$

doi:10.1016/S0022-5223(03)00105-3
Objectives: In a randomized clinical trial of patients undergoing elective coronary artery bypass grafting, we evaluated the effect of intraoperative whole blood sequestration and autotransfusion on postoperative blood loss and the use of allogeneic blood products.

Methods: Male patients were included if it was possible to obtain at least $500 \mathrm{~mL}$ of autologous blood. For patients in group $\mathrm{H}$ (heparin autotransfusion, 50 patients; mean age $59 \pm 8$ years), an average of $670 \pm 160 \mathrm{~mL}$ heparinized blood was drawn before bypass and reinfused after the period of the extracorporeal circulation. For patients in group $C$ (citrate autotransfusion, 48 patients; mean age $60 \pm 10$ years), $450 \pm 109 \mathrm{~mL}$ of citrate blood, drawn before administration of heparin, was used. Controls (N-group) consisted of 46 patients aged $62 \pm 8$ years. Strict transfusion criteria were used, and blood loss and use of allogeneic blood products during the hospital stays of all patients were recorded. Mean differences with their 95\% confidence intervals adjusted for potential confounders were obtained by multiple linear regression.

Results: The mean difference (95\% confidence interval) of blood loss of group $\mathrm{H}$ minus $\mathrm{N}$ was $-93 \mathrm{~mL}$ ( -307 to 139 ) and for $\mathrm{C}$ minus $\mathrm{N}$ was $-66 \mathrm{~mL}$ ( -186 to 179). The mean number of allogeneic blood transfusions for group $\mathrm{H}$ was $0.85 \pm$ 1.74. Group $\mathrm{C}$ and group $\mathrm{N}$ used $0.94 \pm 1.56$ and $0.84 \pm 1.24$.

Conclusion: In coronary artery bypass grafting there is no effect of heparin or citrate intraoperative whole blood sequestration with regard to blood loss or use of allogeneic blood.

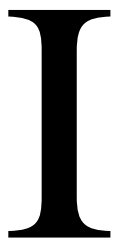

$\mathrm{n}$ recent years, the interest in blood-saving strategies has increased greatly because of the recognition of deleterious effects on health (acquired immunodeficiency syndrome and immunosuppression), as well as the cost aspects of blood transfusion. Coronary artery bypass grafting (CABG) has always claimed a considerable percentage of blood donations. Fresh blood autotransfusion and hemodilution have been investigated for their effect in CABG to reduce the number of blood donations. Several studies show remarkable reductions in allogeneic blood use. ${ }^{1-4}$ However these studies are sometimes outdated, not randomized or controlled, or are inconclusive. Some authors suggest inconclusive results regarding the effect of autotransfusion from the use of heparin as an anticoagulation method. ${ }^{5,6}$ The aim of our trial was to evaluate the effectiveness of intraoperative whole blood sequestration, comparing heparin and citrate as anticoagulants, for decreasing blood loss and use of allogeneic blood products. 


\section{Material and Methods \\ Study Design}

A randomized, partly blinded clinical trial was performed in a peripheral hospital, with all consecutive patients scheduled for CABG during a 6-month period. After written informed consent was obtained, patients were randomized over three groups. This was achieved by block-randomization with concealed envelopes. All data were registered by an independent investigator, and the intensive care unit (ICU) staff on the ward was blinded for the randomization. The hospital medical ethical committee approved our study design. This was a trial where patients entered the study when they discontinued receiving aspirin at least 7 days before surgery. No antifibrinolytic drugs were used during the trial.

\section{Patients}

All patients scheduled for CABG were included when the following criteria were met: male sex, age between 18 and 75 years, normal left ventricular function test result (tested by echocardiography), and an adequate hematocrit level and weight to allow withdrawal of at least $500 \mathrm{~mL}$ of whole blood. Calculations were based on the preoperative hematocrit level, estimated circulating blood volume $(70 \mathrm{~mL} / \mathrm{kg}$ body weight is $\mathrm{A}$, see formula), the priming of the cardiopulmonary bypass (CPB) $(2000 \mathrm{~mL})$, and an estimation of the volume of cardioplegic solution needed (1000 $\mathrm{mL}$ ). We used the formula $A \times$ preoperative hematocrit level $-B$ $\times 0.25$ to determine the blood volume that could be safely donated by each patient. $B$ is the value $3000 \mathrm{~mL}$, cardioplegia and pumppriming values combined, and 0.25 is the aimed lowest hematocrit value during bypass. Exclusion criteria were coronary artery main stem disease, liver disease, and known or suspected bleeding disorders.

\section{Interventions}

There were three treatment arms: a heparin autotransfusion group (H group), a citrate autotransfusion group ( $\mathrm{C}$ group), and a control group (no autotransfusion, $\mathrm{N}$ group). In the $\mathrm{C}$ group, blood was withdrawn before the initiation of the $\mathrm{CPB}$ and administration of heparin. This blood was collected in routine citrate suspension to prevent clotting. In the $\mathrm{H}$ group, blood withdrawal was conducted after administration of heparin through the $\mathrm{CPB}$ before starting the CPB. It is clear that the heparin was used as the anticoagulant for the harvested fresh blood in this group. For both autotransfusion groups, normal aseptic guidelines were followed during harvesting. The blood was kept at room temperature to keep the platelet function as optimal as possible. The targeted hematocrit level for hemodilution for all patients was $25 \%$. The need for fluid infusion was closely monitored by the attending anesthesiologist; if necessary extra saline solution was infused. The fresh autologous blood was returned to the patient after protamine was given to the patient at the end of the operation.

\section{Transfusion Guidelines}

Extensive postoperative bleeding in our department is defined as more than $500 \mathrm{~mL}$ lost in the first postoperative hour, more than $400 \mathrm{~mL}$ lost in the second hour, or more than $300 \mathrm{~mL}$ lost in the third hour. Packed cells were given if the patient had a hematocrit level lower than 0.25 in the postoperative period combined with extensive bleeding. Fresh frozen plasma (FFP) was given with an international normalized ratio (INR) greater than 1.6 and extensive bleeding. The indication for platelet transfusion was a platelet number less than 80 combined with extensive bleeding.

\section{Other Standard Procedures}

Anesthesia was standardized to a benzodiazepine-medium opioid and pancuronium scheme. Blood pressure was regulated with sodium nitroprusside, and nitroglycerin $1 \mathrm{mg} / \mathrm{hour}$ was infused routinely. Before cannulation of the aorta, heparin $300 \mathrm{IE} / \mathrm{kg}$ body weight was given to achieve an actual clotting time (ACT) of more than 450 seconds. The ACT was measured with a Hemo-Chron 401 (Technidyne Corp, Edison, NJ). CPB was standardized with pump flows of $2.4 \mathrm{~L} \cdot \mathrm{min}^{-1} \cdot \mathrm{m}^{-2}$. Body surface area (BSA) at $32^{\circ} \mathrm{C}$ nasopharyngeal temperature and a membrane oxygenator were used. Pump prime and cardioplegic solution were standardized and contained no blood. Only moderate hypothermia down to $28^{\circ} \mathrm{C}$ nasopharyngeal temperature was used.

\section{Data Collection, Statistical Analysis, and Sample Size Calculation}

Operation variables, number of bypasses, use of the internal thoracic artery, total clamping time, and total CPB time were recorded. At the ICU department, patients were monitored for blood loss, use of allogeneic blood or blood products, hemodynamic parameters, use of intra-aortic balloon pump (IABP), urine production, need of ventilation, extubation time, need of rethoracotomy, and number of days in the ICU and the postoperative clinical ward. Hematologic and coagulation parameters were collected 1,3, and 12 hours after surgery and at 1,2, and 7 days after surgery. Possible blood donations in the postoperative ward and side effects of autotransfusion were registered. Statistical evaluation took place with the SPSS statistical battery (SPSS, Inc, Chicago, Ill), in which mean and standard deviations, mean difference, and the 95\% confidence intervals were calculated. We used multiple linear regression to evaluate confounding factors. To detect a clinically significant 300-mL difference in blood loss, with an Alfa of .05 , a power $80 \%$, and a standard deviation of $450 \mathrm{~mL}$, we calculated that we needed at least 40 patients in each group.

\section{Results}

During the period of our study, 397 men were scheduled for CABGs, and only $144(36.3 \%)$ patients met the inclusion criteria. The reasons for exclusion, before the start of the study, were a hematocrit level too low for allowing intraoperative blood donation $(\mathrm{n}=110)$, a decreased left ventricular function $(\mathrm{n}=51)$, renal or hepatic disorder $(\mathrm{n}=$ 34 ), use of heparin before the operation because of unstable angina pectoris $(n=27)$, lack of informed consent $(n=9)$, and miscellaneous $(n=22)$. After randomization, no patients were excluded from the study or analysis of data. Forty-six, 50, and 48 patients were randomized to the $\mathrm{N}$ (normal control subjects), $\mathrm{H}$, and $\mathrm{C}$ groups, respectively, and all groups were comparable for the baseline characteristics as shown in Table 1. There was a difference in the amount of blood collection for patients in the $\mathrm{C}$ and $\mathrm{H}$ groups. The reason for this was that it was easier to collect 
TABLE 1. Preoperative and intraoperative baseline-characteristics of patients in the 3 groups: mean (SD)

\begin{tabular}{lccc}
\hline & N (n = 46) & H (n = 50) & C (n = 48) \\
\hline Age (y) & $61.9(8.1)$ & $58.3(8.1)$ & $59.5(9.6)$ \\
Weight (kg) & $84(7)$ & $86(8)$ & $83(10)$ \\
Plasma sodium (mmol/L) & $139(2)$ & $140(2)$ & $139(2)$ \\
Plasma creatinine (mmol/L) & $100(16)$ & $97(14)$ & $96(14)$ \\
ASAT (U/L) & $17(7)$ & $18(14)$ & $17(9)$ \\
Operating time (min) & $256(62)$ & $270(86)$ & $250(57)$ \\
CPB time (min) & $103(34)$ & $105(41)$ & $96(35)$ \\
Aorta clamp time (min) & $70(28)$ & $75(34)$ & $67(27)$ \\
No. of anastomoses & $6(1)$ & $5(1)$ & $5(1)$ \\
Use internal thoracic artery & 41 & 44 & 45 \\
$\quad$ (No. of patients) & & & \\
Decreased left ventricular & 2 & 0 & 1 \\
$\quad$ function (No. of patients) & & & \\
Volume of blood donation & 0 & $670(160)$ & $450(109)$ \\
$\quad$ (mL) & & & \\
\hline
\end{tabular}

blood from the $\mathrm{H}$ group during $\mathrm{CPB}$. For C-group patients, collection was done before bypass through a wide-bore intravenous catheter residing in the internal jugular vein.

Blood loss in the control group $(\mathrm{N})$ and the autotransfusion groups ( $\mathrm{H}$ and $\mathrm{C}$ ) were comparable (Table 2). The mean blood loss in the control group was $931 \mathrm{~mL}$. In the $\mathrm{H}$ and $\mathrm{C}$ groups, the average blood loss was $1024 \mathrm{~mL}$ and 997 $\mathrm{mL}$, respectively. The mean difference $(95 \%$ confidence interval) of blood loss of between the $\mathrm{N}$ and $\mathrm{H}$ groups was $-93 \mathrm{~mL}$ ( -307 to $139 \mathrm{~mL}$ ) and for $\mathrm{N}$ and $\mathrm{C}-66 \mathrm{ml}(-187$ to $179 \mathrm{~mL}$ ). There were no outliers with regard to blood loss and use of allogeneic blood products in the three groups. Table 2 also shows that there was no reduction in postoperative allogeneic transfusions.

The number of packed cells transfused during the postoperative period were 39,43 , and 45 units for the $\mathrm{N}, \mathrm{H}$, and $\mathrm{C}$ groups, respectively. The percentages of patients that did not receive homologous blood transfusions in groups $\mathrm{H}, \mathrm{C}$, and $\mathrm{N}$ were $70 \%, 63 \%$, and $62 \%$, respectively. The mean number of transfusions was $0.85 \pm 1.74$ in the $\mathrm{H}$ group, $0.94 \pm 1.56$ in the $\mathrm{C}$ group, and $0.84 \pm 1.24$ in the $\mathrm{N}$ group. The mean difference was $-0.02(-0.06$ to 0.6$)$ for $\mathrm{N}$ minus $\mathrm{H}$ and -0.09 ( -0.7 to 0.5$)$ for $\mathrm{N}$ minus $\mathrm{C}$.

The units of FFP used in the autotransfusion groups were comparable in the three groups (Table 2). Platelet donations were more frequently used in the control group when compared with citrate autotransfusion, but statistical significance was not reached (Table 2).

Figure 1 shows the hemoglobin level for the three groups of patients during the intraoperative and postoperative period. The hemoglobin level for all three groups showed an expected drop at the end of the CPB. There were no significant differences between the groups. Figure 2 shows the mean values of the platelet number during and after operation. There are no significant differences among the $\mathrm{H}, \mathrm{C}$, and $\mathrm{N}$ groups. Figure 3 shows the intraoperative and postoperative ACT. We observed an initial increase in ACT at the end of CPB when the heparin had not yet been antagonized. There were no significant differences among the groups.

The IABP was not used in any of the patients. There was no change in the incidence of repeat thoracotomy for bleeding. The incidence of repeat thoracotomy in the control group was $4.3 \%$ and was comparable with the $2.0 \%$ and the $6.3 \%$ of the autotransfusion groups. The mean duration of artificial ventilation for all patients was $11 \pm 6$ hours, the mean ICU stay was $2.4 \pm 1.2$ days, and the total hospital stay was $6.2 \pm 2.5$ days, with no significant differences among the groups. No side effects were recorded in the autotransfusion groups, and none of the patients died after surgery.

\section{Discussion}

This study demonstrated that the use of fresh autologous blood, administered during the operation with heparin or citrate anticoagulation, is not effective in reducing either the need for allogeneic blood or the postoperative blood loss. Postoperative bleeding is believed to be partly due to the deleterious effects of $\mathrm{CPB}$ on platelet function because of activation of the clotting system. ${ }^{7-9}$ Finding no effect of autotransfusion may be due to bias in our study protocol.

We tried to minimize information bias by using one person to obtain the data, strict transfusion criteria, and blinding the staff responsible for homologous blood transfusions. We restricted confounding bias by use of multiple regression to adjust for potential confounding factors. It is possible that our inclusion criteria, donation of at least 500 $\mathrm{mL}$ blood, may have led to a "healthier" group or a group of patients with a low risk of postoperative bleeding and use of allogeneic blood use. Some randomized trials ${ }^{10,11}$ focused retrospectively during their analysis on the question of whether intraoperative blood sequestration was beneficial, in a subgroup of patients undergoing $\mathrm{CABG}$ with a high risk for postoperative bleeding or use of allogeneic blood, and found a positive effect. However, we know the value of retrospective studies.

Another reason for finding no effect could be that we performed less optimal hemodilution. Petry and associates ${ }^{12}$ found an effect after randomization; they autotransfused patients with their own blood after hemodilution until a hematocrit level of $20 \%$ was reached. One quarter of our patients had the lowest hematocrit level during bypass (between $18 \%$ and $20 \%$ ). Our department aimed at a hematocrit level of $25 \%$ to avoid hazardous and negative outcomes for the patients. According to our data on hemostasis and the coagulation profile during the postoperative period, we do not expect that a lower hematocrit level would lead to a beneficial effect because we could not observe any small 


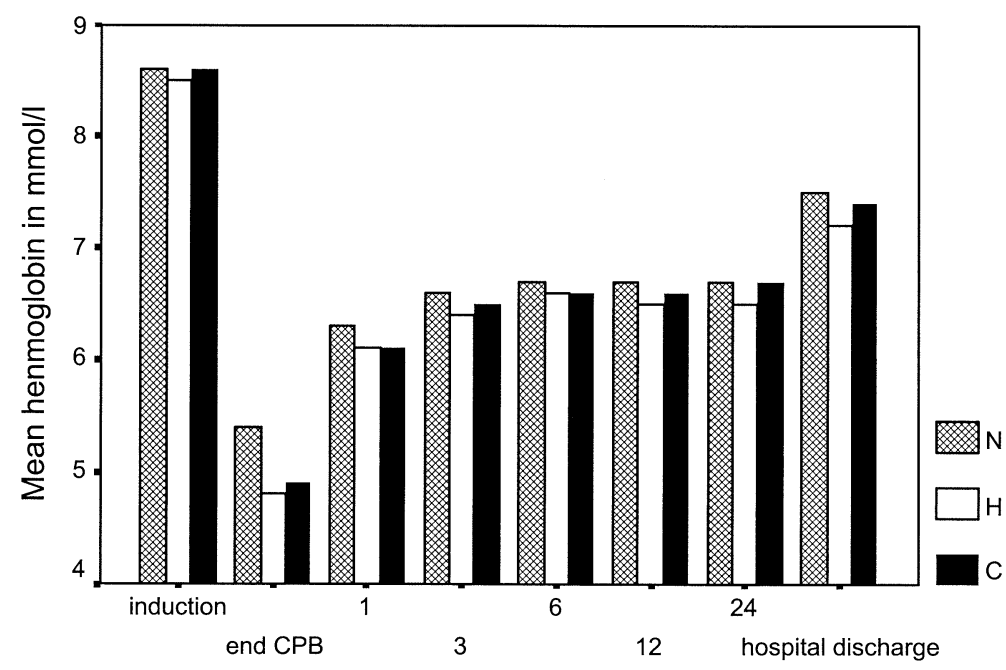

Hours after surgery

Figure 1. Mean hemoglobin level during and after surgery.

TABLE 2. Blood loss and use of blood products: mean differences (S.D.) between intervention groups and control subjects

\begin{tabular}{|c|c|c|c|c|c|c|}
\hline & H & C & $\mathbf{N}$ & Mean difference & $95 \% \mathrm{CI}$ & $P$ value \\
\hline Blood loss, mL & $1024 \pm 576$ & $997 \pm 475$ & $931 \pm 483$ & $\begin{array}{l}-93^{*} \\
-66 \dagger\end{array}$ & $\begin{array}{l}-307-139 \\
-186-179\end{array}$ &. .5 \\
\hline Packed red cells, units & 43 & 45 & 39 & $-0.01^{*}$ & $-0.06-0.6$ & 1 \\
\hline Units/patient & 0.85 & 0.94 & 0.85 & $-0.09 \dagger$ & $0.7-0.5$ & .8 \\
\hline FFP, units & 12 & 13 & 11 & $-0.01^{*}$ & $-0.29-0.29$ & 1 \\
\hline Units/patient & 0.24 & 0.27 & 0.24 & $-0.03 \dagger$ & $-0.3-0.3$ & .8 \\
\hline Platelets (5 units) & 4 & 2 & 5 & $0.03^{*}$ & $-0.12-0.2$ & .7 \\
\hline Units/patient & 0.08 & 0.04 & 0.11 & $0.07 \dagger$ & $-0.06-0.2$ & .3 \\
\hline
\end{tabular}

$F F P$, Fresh frozen plasma.

${ }^{*} \mathrm{~N}$ vs $\mathrm{H}$ group.

tN vs. C-group.

positive hemostatic effects. In addition, lowering the hematocrit level during bypass to a value of, for example, $18 \%$ will decrease oxygen-carrying capacity to a dangerous level for the patient.

Others ${ }^{5,6}$ emphasized that the use of heparin as anticoagulant is the reason that a possible effect of fresh blood autotransfusion could not be measured. We tried to overcome the problem and used citrate autotransfusion. With the claim of reaching good hemostatic effects with citrate and heparin autotransfusion of fresh blood, ${ }^{1-4}$ we expected that patients receiving autotransfusion would benefit. However, we could not confirm this. There is still a $5 \%$ chance that our results are not true and that there is a beneficial effect of intraoperative whole blood sequestration and autotransfusion in patients undergoing CABG.

Randomized clinical trials evaluating the effect of fresh autologous blood transfusions are scarce and inconclusive. ${ }^{1,3,11,13}$ In 237 patients undergoing CABG, Wasser and colleagues $^{11}$ found differences in hemoglobin levels and platelet count, but these were small and without clinical significance in patients undergoing autotransfusion. Scezsi and associates ${ }^{14}$ in 1989 and Kochamba and associates ${ }^{13}$ in 1996 reported a positive effect of fresh blood autotransfusion. Reductions for allogeneic blood with $40 \%$ and $45 \%$, respectively, were reached. Postoperative blood loss was reduced in these trials, with $24 \%$ and $28 \%$ compared with control subjects. However, it should be noted that Scezsi and associates ${ }^{14}$ did not use strict transfusion criteria or blinding to control for information bias, whereas Kochamba and associates ${ }^{13}$ did. Others ${ }^{15,16}$ used strict transfusion criteria but included a small amount of patients during their trial-35 and 30 patients, respectively. So we must be careful with interpretations.

In a study by Ovrum and colleagues, ${ }^{4}$ less than $3 \%$ of patients needed allogeneic donations during their postoperative hospital stay. Important differences from our study 


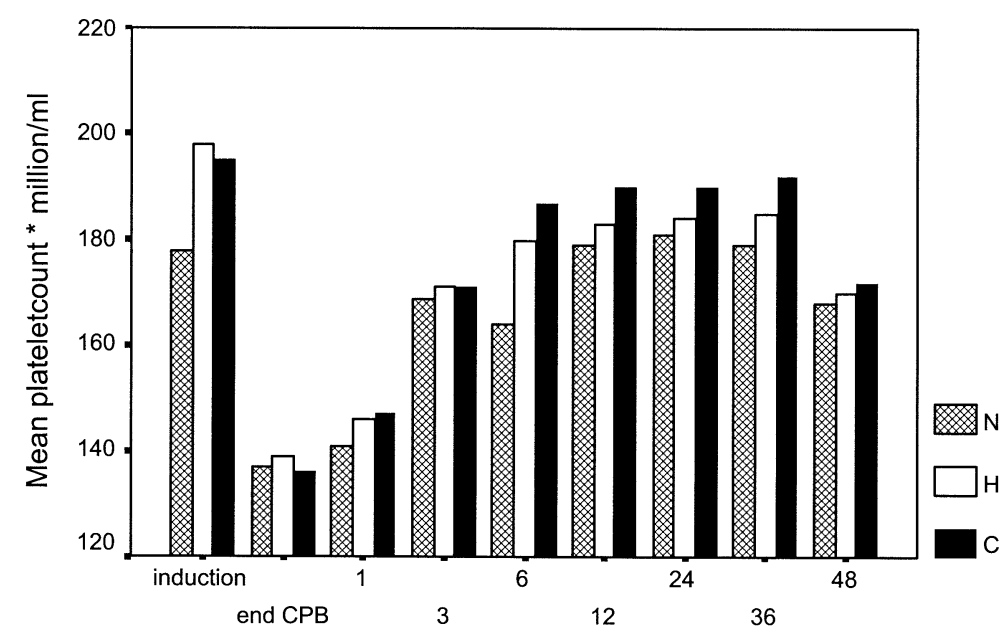

Hours after surgery

Figure 2. Mean platelet level during and after surgery.

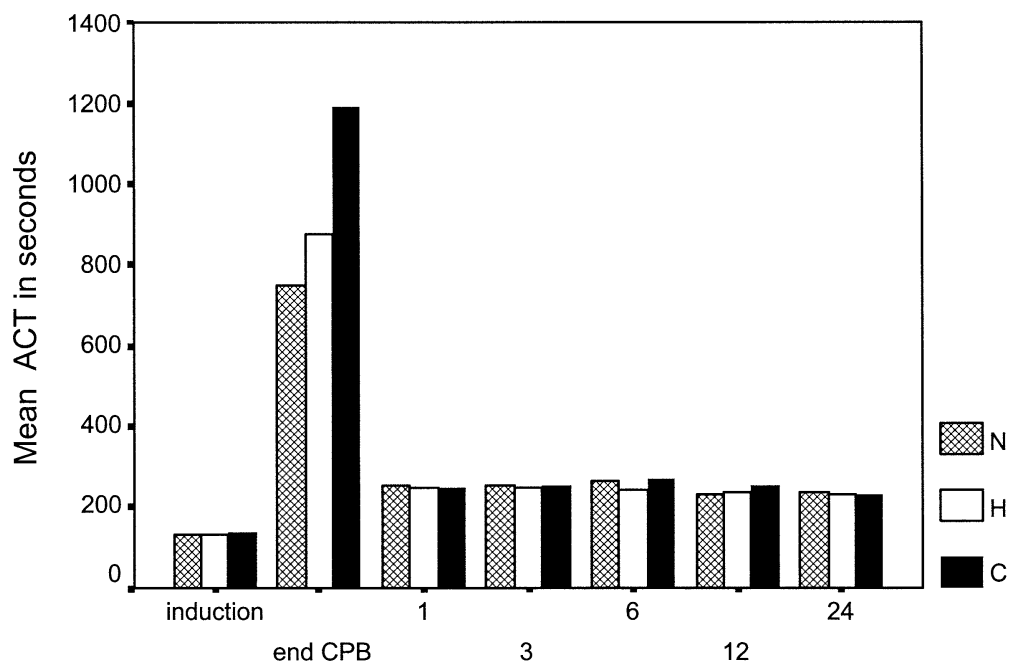

Hours after surgery

Figure 3. Activated clotting time during and after surgery.

include their use of fresh heparinized autologous blood combined with shed mediastinal blood; furthermore, their study was not randomized controlled. Others ${ }^{17}$ could not find an additional effect of autotransfusion of shed mediastinal blood, and clinical problems such as fever, immunologic reactions, disturbances in laboratory measurements (creatine kinase [CK] and alanine aminotransferase [ALAT] values), wound infections, ${ }^{18-20}$ and even excessive bleeding may occur. ${ }^{21}$ The rationale of using fresh blood without shed mediastinal blood is that activation of platelets and coagulation factors is prevented and improves postoperative hemostasis. ${ }^{22}$ However, we and others ${ }^{11}$ did not observe any positive changes regarding the hemostasis profile or platelet count with patients receiving autotransfusion.

The value of reducing blood loss and use of allogeneic blood was recently reappraised by Michalopoulos and colleagues. ${ }^{23}$ They found that the use of allogeneic blood has a deleterious effect on survival after CABG. The mortality rate increased if blood donations were needed in conjunction with inotropic agents in the immediate postoperative period. The preoperative level of hemoglobin is known to be the best predictor of the blood loss and need of allogeneic blood. ${ }^{24}$ Other predicting factors that are influencing the use of allogeneic blood remain to be discovered. With this trial 
we have one answer already. Intraoperative whole blood sequestration, anticoagulated with heparin or citrate, does not have a positive effect in patients undergoing CABG when a mean volume of $670 \mathrm{~mL}$ or $450 \mathrm{~mL}$ is used in patients at low risk. Whether there is an effect with the same or larger volume of blood donated in patients at high risk is yet to be examined in prospective randomized trials. A main limitation of intraoperative whole blood sequestration and autotransfusion seems to be the applicability towards the patients. In our study, only $36.2 \%$ of the patients were eligible for blood donation.

In conclusion we can say that there is no positive effect of intraoperative whole blood sequestration and autotransfusion in male patients undergoing CABG with regard to blood loss, use of allogeneic blood, and hemostasis. The clinical implication is that this technique is not indicated in the patients at low risk. In the future, patient trials regarding aggressive blood salvage techniques should focus on patients with a high risk for blood loss and use of allogeneic blood.

\section{References}

1. Ochsner JL, Mills NL, Leonard GL, Lawson N. Fresh autologous blood transfusions with extracorporeal circulation. Ann Surg. 1973; 177:811-7.

2. Cohn LH, Fosberg AM, Anderson WP, Collins J. The effects of phlebotomy, hemodilution, and autologous transfusion on systemic oxygenation and whole blood utilization in open-heart surgery. Chest. 1975;68:283-7.

3. Hallowell P, Bland JHL, Buckley HJ, Lowenstein E. Transfusion of fresh autologous blood in open-heart surgery: a method for reducing bank blood requirements. J Thorac Cardiovasc Surg. 1972;64:941-8.

4. Ovrum E, Am Holen E, Tangen G. Consistent nonpharmacologic blood conservation in primary and reoperative coronary artery bypass grafting. Eur J Cardiothorac Surg. 1995;9:30-5.

5. Pliam MB, McGoon DC, Tarhan S. Failure of transfusions of autologous whole blood to reduce banked blood requirements in open-heart surgical patients. J Thorac Cardiovasc Surg. 1975;1970:338-43.

6. Sherman MM, Dobnik DB, Dennis RC, Burger RL. Prediction of hematocrit changes in hematocrit changes in open-heart surgery without blood transfusion. J Cardiovasc Surg (Torino). 1984;25:545-8.

7. Michelson AD, MacGregor H, Barnard MR, Kestin AS, Rohrer MJ, Valeri CR. Reversible inhibition of human platelet activation by hypothermia in vivo and in vitro. Thromb Haemost. 1994;71:633-40.

8. Mazer CD, Horstein A, Freedman J. Platelet activation in warm and cold heart surgery. Ann Thorac Surg. 1995;59:1481-6.
9. Shore-Lesserson L. Aprotonin has direct platelet protective properties: fact or fiction? Eur J Cardiothorac Vasc Anesth. 1999;13:379-81.

10. Ferraris VA, Berry WR, Klingman RR. Comparison of blood reinfusion techniques used during coronary artery bypass grafting. Ann Thorac Surg. 1993;56:433-39.

11. Wasser MNJM, Houbiers JGA, d'Amaro J, Hermans J, Huysmans A, van Konijnenburg GC, et al. The effect of fresh versus stored blood on postoperative bleeding after coronary bypass surgery: a prospective randomized study. Br J Haematol. 1982;72:81-4.

12. Petry AF, Jost J, Sievers H. Reduction of homologous blood requirements by blood pooling at the onset of cardiopulmonary bypass. J Thorac Cardiovasc Surg. 1994;107:1210-4.

13. Kochamba GS, Pfeffer TA, Sintek CF, Khonsari S. Intraoperative autotransfusion reduces blood loss after cardiopulmonary bypass. Ann Thorac Surg. 1996;61:900-3.

14. Scezsi J, Batonyi E, Liptay P, Orosi P, Medgyessy I, Peterty A. Early clinical experience with a simple method for autotransfusion in cardiac surgery. Scand J Thorac Cardiovasc Surg. 1989;23:51-6.

15. Ward HB, Smith RAR, Landis KP, Nemzek TG, Dalmasso AP, Swaim WR. Prospective randomized trial of autotransfusion after routine cardiac operations. Ann Thorac Surg. 1993;56:137-41.

16. Olsfanger D, Fredman B, Goldstein B, Shapiro A, Jedeikin R. Acute normovolaemic haemodilution decreases postoperative allogeneic blood transfusions after total knee replacement. Br J Anesth. 1997;79: 317-21.

17. Morris JJ, Tan YS. Autotransfusion: is there a benefit in a current practice of aggressive blood conservation? Ann Thorac Surg. 1994; 58:502-7.

18. Adan A, Brutel de la Riviere A, Haas F, van Zalk A, de Nooij E. Autotransfusion of drained mediastinal blood after cardiac surgery; a reappraisal. Thorac Cardiovasc Surg. 1988;36:10-6.

19. Bouboulis N, Kardara M, Kesteven PJ, Jayakrishnan AG. Autotransfusion after coronary artery bypass surgery: is there any benefit? J Cardiac Surg. 1994;9:314-21.

20. Body SC, Birmingham J, Parks R, Ley C, Maddi R, Shernan SK, et al. Safety and efficacy of shed mediastinal blood transfusion after cardiac surgery: a multicenter observational study. J Cardiothorac Vasc Anesth. 1999;13:410-6.

21. Wahl GW, Feins RH, Alfieres G, Bixby K. Reinfusion of shed blood after coronary operations causes elevation of cardiac enzyme levels. Ann Thorac Surg. 1992;53:625-7.

22. Mohr R, Goor DA, Yellin A, Moskovitz Y, Shinfeld A, Martinowitz U. Fresh blood units contains large potent platelets that improve hemostasis after open-heart operations. Ann Thorac Surg. 1992;53: 650-4.

23. Michalopoulos A, Tzelepis G, Dafni U, Geroulanos S. Determinants of hospital mortality after coronary artery bypass grafting. Chest. 1999; 115:1598-603.

24. Yamamuro M, Kudou K, Hosoda Y, Nukariya M, Sasaguri S, Watanabe $\mathrm{M}$, et al. Determinants of homologous blood utilization in addition to autologous blood transfusion: a multivariate study [Japanese]. J Japan Assoc Thorac Surg. 1994;42:1123-31. 